\title{
Correction to: "The Battle is on": Lakatos, Feyerabend, and the student protests
}

\author{
Eric C. Martin ${ }^{1}$ \\ Published online: 17 January 2020 \\ (C) Springer Nature B.V. 2020
}

\section{Correction to: European Journal for Philosophy of Science (2019) 9:28 https://doi.org/10.1007/s13194-019-0251-y}

The following correction will help establish more clearly and fully the ways in which I drew on Matteo Collodel's work in the composition of this paper. We were researching similar topics and I was acquainted with Dr. Collodel's achievements as I participated in the event in which he presented them publicly and he was so kind to share them with me in private. It is my fault that I did not ask Dr. Collodel's permission to use and disseminate in print unpublished results of his research before submitting or publishing this paper, thereby also losing the chance to make these amendments in the original publication.

The full reference to Matteo Collodel's work is:

Collodel, M. (2015). Flippant anarchism: Feyerabend and the student movement. Unpublished paper presented at the conference Feyerabend 2015: Forty Years 'Against Method', Durham University, July 15, 2015. https://www.academia.edu/13706500/Flippant_ Anarchism_Feyerabend_and_the_Student_Movement. Retrieved, March 1, 2019.

I would like give reference to this work in the following notes in my article:

- n2: Two exceptions include Lee Congdon's (2002) article on Lakatos's turn toward conservative politics, and Matteo Collodel's excellent (2015) on which section 3 is largely based.

- n42: PKF to IL, 11 Aug 1969, quoted in Collodel (2015).

- n43: PKF to Hans Albert, 20 Apr 1968, quoted in Collodel (2015); translated from German by Collodel.

The online version of the original article can be found at https://doi.org/10.1007/s13194-019-0251-y

Eric C. Martin

eric_martin@baylor.edu

1 Baylor University, Waco, TX, USA 
- n48: PKF to IL, 3 Mar 1969, quoted in Collodel (2015).

- n49: PKF to Agassi, 23 Jun 1968, quoted in Collodel (2015).

- n50: "I would not participate in a Popperian collection simply because I do not intend to join any party... A collection of the kind you suggest would be a step towards institutionalization - and therefore I cannot see any way towards being a part of it." PKF to IL, 27 Jul 1968, quoted in Collodel (2015).

- n51: PKF to Agassi, 11 Jun 68, quoted in Collodel (2015).

- n52: PKF to IL, 30 Jul 1968, quoted in Collodel (2015).

- n53: PKF to IL, 13 Aug 1968, quoted in Collodel (2015).

- n54: PKF to IL, 20 Aug 1968, quoted in Collodel (2015).

- n55: PKF to IL, 17 Jun 68, quoted in Collodel (2015).

- n56: Quoted in Collodel (2015).

- n57: PKF to IL, 18 Nov 1968, quoted in Collodel (2015).

- n58: PKF to Agassi, 8 Nov 1968, quoted in Collodel (2015).

- n60: PKF to Rudolf Kaehr, 9 Dec 1968, quoted in Collodel (2015).

- n62: PKF to IL, 4 Aug 1969, quoted in Collodel (2015). Feyerabend's intellectual self-conception evolved through the years. In the 1980s he defended relativism, while by the time of his late work, he considered his philosophy a kind of "mysticism." See Heller (2016) and Martin (2016).

- n63: PKF to IL, 12 Dec 1969, quoted in Collodel (2015).

- n64: PKF to IL, Jan 1969, quoted in Collodel (2015).

- n65: PKF to IL, 30 Apr 1969, quoted in Collodel (2015).

- n68: PKF to IL, 20 Feb 1970, quoted in Collodel (2015).

- n69: PKF to IL, 14 Feb 1969, quoted in Collodel (2015).

- n78: PKF to IL, 1 Nov 1968, quoted in Collodel (2015).

Publisher's note Springer Nature remains neutral with regard to jurisdictional claims in published maps and institutional affiliations. 